\section{LOOKING AT HUMAN WICKEDNESS}

\section{Aggression and Defence}

Neural Mechanisms and Social Patterns. By Carmine D. Clements and Donald B. Lindsley. (UCLA Forum in Medical Sciences, No. 7.) Pp. xv +361 . (University of California Press: Berkeley and Los Angeles; Cambridge University Press: London, 1967.) 142s. 6d.

There is no doubt that we are learning more and more about aggression in human beings, but the time when all these pieces of information from sociology, neuro-endocrinology, neurology and so forth can be woven into a comprehensive whole is still a long way off. It is not peculiar of this age that man should worry about his potential for killing but the amount of effort being expended in the study of causation and origin of this fatal flaw in his character is surely remarkable. Perhaps this is because of the mounting cost of aggression to the community; sheer economics begins to support the moral arguments.

This symposium was naturally no more successful than any other recent one on this subject; the participants cannot be said to have produced even a consensus of opinion. But the characterization and evaluation of the various approaches is most valuable; probably the physiology and neurology of human aggression is put at more length here than previously.

It has become almost obligatory to discuss animal aggression in this search for a rostrum. For this purpose a distinction is made between predation and inter-individual aggression, but this seems to be an intuitive and thoroughly anthropomorphic distinction the value of which seems to be highly questionable when the results of brain stimulation are considered. Leakey, in his consideration of the role of aggression in human evolution, maintains that Homo habilis regularly attacked giant baboons as prey and suggests that it was but a short step to attacking his own kind. Furthermore, the very characterization of aggression in animals is on the human model, to then parallel it with human behaviour seems a somewhat circular argument. The spectrum of behaviour which constitutes not only the grades but also the types of aggression in humans is beautifully characterized in Plog's report on the Watt's riots where looters were seen to respect traffic lights in the midst of their highly aggressive behaviour; anarchy did not take complete control. Welch, in part of the discussion, suggests that the state of aggressiveness should be perhaps distinguished from the act of aggression. This measure of subtlety is achievable in human beings but, though necessary, can hardly be attained in animal studies.

This work is well reviewed in papers by Barnett and Eibl-Eibesfeldt and is shown to be biologically adaptive (not a "bad habit"). Though Cetacea are not at all fre. quently seen to fight, indirect evidence adduced by Norris seerns to show conclusively that they are not exceptional among animals. Kawamura gives a careful and interesting account of aggression in Japanese monkeys including some remarkable observations of attacked monkeys enlisting the aid of their attacker to aggress against a third. These monkeys also will attack in troops; aggression is not solely an inter-individual affair.

Brain stimulation may produce complete or partial patterns of aggressive behaviour when the electrodes are in parts of the brain stem and hypothalamus, as Kaada describes. But the results of stimulation are often influenced by the environment in which the animal finds itself; the electric current does not throw a switch, as it were, bringing into action aggression; it occurs only if it is appropriate in that particular situation. Delgado's studies of radio-stimulation of parts of the brain in monkeys which are therefore not constrained by wires lead him to postulate mechanisms for aggressive drive different from those for the performance of aggressive acts. These neurologists do not oversimplify their problems, realizing as they do the influence of the hormone levels in the animal and the incoming sensory information. Rothballer considers the specific role of neurohumours; Berkowitz describes the experiments on the effect of seeing aggression take place on subsequent behaviour of his human subjects, while Brosin takes a psychiatrist's view of the control of aggression by religions and so forth at various stages in human history. Finally, Laswell presents his inter. national lawyer's view of war as "the distinctive institution of a divided world".

Much of the long discussions reported at the ends of the papers is very useful and sustains the stimulation which the papers must cause the reader. Sometimes the argument becomes formless and the hard edge of critical thought is blunted, but there is an air of sincerity even in the purple passages.

J. D. Carthy

\section{REACTIONS TO INJURY}

The Pharmacology of Inflammation

By W. G. Spector and D. A. Willoughby. (Modern Medicine.) Pp. ix +123 . (English Universities Press: London, 1968.) 40s.

This book is about the endogenous humoral factors in inflammation, rather than about drugs which may influence this process. Inflammation is defined as "the local reaction to injury of the living microcirculation and its contents". Some workers may consider this definition too narrow.

A brief summary of the more important historical developments is followed by a discussion of the intimate mechanism of increased vascular permeability. This chapter includes the beautiful electron microscopic evidence, obtained by the late Lord Florey and his colleagues, of the passage of blood cells through endothelial gaps in the vascular wall.

The examination of the individual endogenous substances is guided by the authors' useful criteria for accepting factors as mediators of inflammation. These are listed on page 5 and re-stated more fully on page 22: the postulated mediator should exert the appropriate effects and should be detectable only during inflammation; its specific antagonists should also suppress the changes attributed to it; these changes should not occur after previous removal of the substance from tissues. The sections on histamine and on the polypeptides kinins deal with the distribution of these agents, properties relevant to inflammation, liberation and the evidence for their participation in inflammation. A full account is given of the numerous contributions made in this field by the authors and their colleagues. Comparatively little importance is attached to 5-hydroxytryptamine.

The discussion of delayed hypersensitivity centres around the authors' extensive work on the lymph node permeability factor (LNPF) which they consider to be the "leading contender as mediator of these reactions". LNPF can be extracted from many tissues. Besides permeability effects, it induces migration of leucocytes and deposition of fibrinoid. Experiments with antisera against LNPF support the claim that it participates in the tuberculin reaction and other types of delayed hypersensitivity.

Future editions of the book will undoubtedly be improved by more careful editing and proof reading. Kallikrein is a protein and enzyme as stated on page 57. It is not a decapeptide as shown on page 56, where it is also wrongly implied that kallikrein and kallidin are synonymous. The plasma enzyme which destroys the peptides kallidin and bradykinin is a kininase, not a kinase. The section on histamine (page 28) lacks a title; and the first sentence on page 36 lacks a beginning. 